\title{
Mind the Costs: Rescaling and Multi-Level Environmental Governance in Venice Lagoon
}

\author{
Matteo Roggero • Oliver Fritsch
}

Received: 25 November 2008/ Accepted: 25 January 2010/Published online: 17 February 2010

(C) The Author(s) 2010. This article is published with open access at Springerlink.com

\begin{abstract}
Competences over environmental matters are distributed across agencies at different scales on a nationalto-local continuum. This article adopts a transaction costs economics perspective in order to explore the question whether, in the light of a particular problem, the scale at which a certain competence is attributed can be reconsidered. Specifically, it tests whether a presumption of leastcost operation concerning an agency at a given scale can hold. By doing so, it investigates whether the rescaling of certain tasks, aiming at solving a scale-related problem, is likely to produce an increase in costs for day-to-day agency operations as compared to the status quo. The article explores such a perspective for the case of Venice Lagoon. The negative aspects of the present arrangement concerning fishery management and morphological remediation are directly linked to the scale of the agencies involved. The analysis suggests that scales have been chosen correctly, at least from the point of view of the costs incurred to the agencies involved. Consequently, a rescaling of those agencies does not represent a viable option.
\end{abstract}

Keywords Scale $\cdot$ Multi-level governance · Governance costs · Water management · Fishery policy · Agency design

\section{Roggero $(\bowtie)$}

Department of Economics, Helmholtz-Centre for Environmental Research-UFZ, Permoserstrasse 15, 04318 Leipzig, Germany e-mail: matteo.roggero@ufz.de

\section{O. Fritsch}

Department of Policy Analysis, National Environmental Research Institute-DMU, Aarhus University,

Grenaavej 14, 8410 Roende, Denmark

e-mail: olf@dmu.dk

\section{Introduction}

Competences over environmental matters are distributed across agencies ranging from the national to local level: There are fisheries to be preserved, migratory bird species to be monitored, habitats to be maintained, national parks to be managed, and each of those activities can be entrusted to national ministries or agencies, local municipalities, or to some intermediate bodies on a regional level. The choice of the specific level at which to allocate a certain competence, regardless of its actual rationale, has implications for the relation between the agency's territorial jurisdiction and the scale of the activities that the specific competence foresees.

Scholars have advanced several claims concerning that relationship: Young (2002) identifies a "problem of fit" that emerges when politico-administrative jurisdictions, often historically grown and representing political or cultural divisions do not match with the physical reality and hence the scale of what they manage. According to Adler (2005), this is often the case in environmental politics, leading to serious implementation deficits and less effective environmental protection measures. As a consequence, administrative reforms often aim at improving the match between regulatory and ecological scale although this might be at the expense of interplay between authorities operating at an ecosystem level and those operating within traditional jurisdictions (Moss 2003, 2004). The European Union's Water Framework Directive (Directive 2000/60/ EC) constitutes an example of a similar reform: It requires Member States to restructure their management activities on a river basin level (Art. 3). By establishing river basin districts as central administrative units, the directive attempts to match the level of water governance with the physical scale of the watershed resource to be managed. 
While this suggests that both environmentally concerned scholars and the European regulators agree on the general desirability of such a match, we intend to introduce the element of costs in the overall discussion on rescaling. In doing so, we will build upon the perspective proposed by Birner and Wittmer (2004) based on transaction costs economics and focusing on the effects of decentralization and devolution on the costs of running governance structures in natural resource management. The idea is that, along with Olson (1969), rescaling efforts might indeed close gaps in the relationship between agencies (including their tax base) and the scale of the resources they manage (including their respective beneficiaries). What is new, however, is that this may simultaneously increase the monetary and non-monetary costs those very agencies face in going about their daily business. To the extent that more costly day-to-day operations reduce effectiveness in environmental management, this may potentially more than offset the advantages sought after while rescaling. A closer look is in order.

This article will explore whether rescaling is likely to produce an increase in governance costs as compared to the status quo. If that is the case, rescaling does not represent a "solution" but a "shifting" of the problem. An undesirable "mismatch" may have been eliminated via rescaling, though at the cost of greater efforts in running the newly established governance system. In order to explore this possibility, we turn to the case of Venice Lagoon. A scale mismatch between the arrangements regulating fishery management and morphological remediation proves problematic namely in light of the Polluter Pays Principle endorsed by the Water Framework Directive. A rescaling of either arrangement may be necessary. We can, however, show that the present arrangements are likely to represent a least-cost option precisely in the light of their scale, so that rescaling is likely to produce more costly governance arrangements. We hence conclude that, among the policy options available to the Italian decision-makers, governance arrangements shall first be considered which address the present mismatch without involving rescaling. Extending a similar perspective beyond the Venice case, we show here how an analysis of governance cost can help screening scale-related policy options in environmental matters.

The article is organized as follows: In the next section, we will present our theoretical framework combining Olson's theory of fiscal equivalence (1969) with Birner and Wittmer's (2004) work on governance costs and with recent accounts on multi-level governance as put forward by Hooghe and Marks (2003). We will then present the case of Venice Lagoon and the challenges it creates. The last section is dedicated to our conclusions and discusses avenues for further research.

\section{Costs and Scale in Governance Arrangements: Insights from the Literature}

Olson's theory of fiscal equivalence (1969) constitutes the conceptual starting point of this article. The basic argument is that, every time a good is provided where its contributors differ partly or fully from its users, incentives arise for the provision of the good to be resized accordingly. Despite the broader applicability of the concept, the goods that Olson has in mind are those services provided by public authorities for the general public - hence things enjoyed by many and contributed to by many (the taxpayers), deprived however of the one-to-one relationship between demand (beneficiaries) and offer (contributors) otherwise typical in market situations. Textbook examples are public radio stations, or national defense, though the outcomes of the operations of an environmental agency are by no means different. In that case, Olson's rescaling would happen in situations where a national environmental authority, paid for by national taxpayers, enacts a certain policy which happens to benefit only a smaller, localized fraction of the population. According to Olson, nobody wants to pay for a service he or she does not enjoy. Incentives arise for contributors to make use of the appropriate representation channels (e.g. voting) so that the specific competence is assigned to an agency whose jurisdiction (and tax base) encompasses those particular beneficiaries and no one else.

The principle of fiscal equivalence is generally looked at as a normative standard for agency design: It tells us how agencies should be designed. Olson himself suggests, however, that the same principle could, to some extent, explain the duplication of agencies in the U.S. administration of the 1960s, when the article was written (Olson 1969 , p. 487). The principle may, therefore, bear positive explanatory power by laying the foundation on how agencies have been and will be designed. If the principle holds true, we can expect to observe a match of agency jurisdictions, contributors and beneficiaries.

Olson himself is cautious concerning the explanatory power of his concept, and introduces a limiting factor. Specifically, he stresses that the complexity of public policy makes a perfect match of jurisdictions, contributions and beneficiaries impossible. This limits the degree to which fiscal equivalence can be obtained. Intuitively, equivalence comes at a cost for the regulators and that additional cost may be high enough to make a certain degree of disequivalence acceptable (see pp. 485-486). The message we take is hence twofold: First, we can expect a tendency in agency design towards the matching described above. Second, the same tendency will at a certain point stop as an effect of the aforementioned additional cost. 
Olson is certainly not alone in trying to explain the distribution of competencies across multiple, hierarchically organized policy levels. In particular the notion of multilevel governance has gained popularity after alternative, non-hierarchical modes of governance had been identified (Jordan 2001; Papadopoulos 2005). Such arrangements are less in line with the classic federalist notion of what has later been labeled Type I multi-level governance.

According to Marks and Hooghe (2004) who have popularized this dichotomy, Type I governance arrangements are characterized by a limited number of jurisdictions with a distinct, mutually exclusive territorial basis and a long record of competencies for a variety of policy problems. Being incorporated into a hierarchically structured political system, they are characterized by a clear attribution to a constituency through established representation channels: Classical federalist polities are prime examples for this 'Russian doll-like' organization of political power.

Its conceptual counterpart, Type II multi-level governance, often depicted as a 'marble cake', is characterized by entities spanning vertically across levels of political and administrative organization as well as horizontally throughout the public-private divide. Marks and Hooghe (2004) draw a picture of flexible regulatory bodies, often established for a limited time only and serving a single, specified purpose. The design of these agencies, particularly concerning the choice of jurisdiction borders and the related attribution of competencies, does not reflect representation considerations (e.g. clear attribution to a constituency, explicit link to representation channels) as is the case for Type I agencies. Instead, their design adapts and shows flexibility in order to adequately deal with specific tasks, even to the extent of competing with, or duplicating already existing Type I entities. The authors locate Type II forms of multi-level governance in public-private partnerships, fora of transnational cooperation, but also participatory forms of decision making across several policy levels (Marks and Hooghe 2004).

We can now establish a link with Olson's perspective: Fiscal equivalence may explain the distribution of competencies among Type I agencies embedded in a hierarchical system. When, instead, Type II arrangements occur, the matching of jurisdictions, contributors and beneficiaries is far more difficult to establish in comparison to their Type I counterparts. What is more, such identity may possibly come about, but it cannot do so through the mechanism suggested by Olson. This is precisely because of the looser representation profile Type II arrangements involve. Furthermore, the Type I vs. Type II dichotomy is presented in terms of arrangements with a strong representation profile (Type I) as opposed to arrangements with a task-oriented, fit-for-purpose rationale (Type II). This suggests a trade-off between the two dimensions. Take as a reference a certain agency design with a specific representation profile and a corresponding degree of effectiveness in performing a certain task. It is then possible to consider alternative designs that show a weaker representation profile and a higher degree of effectiveness for the same type of activity. Let us now introduce a broad and heterogeneous set of tasks and specific effectiveness targets for all of them. We can then imagine tasks being compatible with a high degree of representation in agency design as well as tasks where the necessary degree of effectiveness is achieved at the cost of a lower degree of representation.

The last considerations make it necessary to further characterize the agencies at hand in relation to the tasks they are set to fulfill. Skelcher (2005, pp. 97-99) helps us here. Building on Marks and Hooghe, he provides a more thorough exploration of Type II multi-level governance forms and distinguishes between "clubs", "polity-forming bodies" and "agencies" (relabeled here 'special agencies' in order to avoid confusion with Type I entities). Special agencies are the most relevant for the purpose of this article as they represent bureaucratic organizations which were established to fulfill a specific task under the political supervision of the central government. Breaking political levels, sectors and territories, their mission is to deliver effective and efficient policies through flexible management outside the boundaries of the pre-existing administrative hierarchy.

Although Skelcher (2005) does not discuss the sources of his typology very extensively, the differences in roles that state agencies are assigned to in Type II settings is striking. While agencies do not play a vital role at all in "clubs", they engage in a communicative and, sometimes, power-sharing relationship with non-state actors in "polityforming bodies". In the third typology, public officials appear in special agencies without direct interaction with stakeholders. This would seem to discourage any attempts to characterize Marks and Hooghe's Type II multi-level settings in relation to agency operations. However, Skelcher's taxonomy allows us to concentrate on the special agency interpretation. We can therefore distinguish Type I from Type II settings in terms of particular tasks being provided by agencies placed within the existing hierarchies (Type I), or by special agencies placed outside them (Type II). This specification allows us to treat the two typologies of governance arrangements in organizational terms, focusing on alternative agency designs and exploring them along the dimension of costs.

Within the scholarly work on the drivers behind new modes of governance political economists have explored an economic rationale for organizing politics, be it within, or beyond traditional hierarchies (Williamson 1999; Paavola and others 2009). Birner and Wittmer (2004), in particular, explore the "efficient boundary of the state" (p. 
667). The goal is to allow for an informed choice on possible trade-offs between representation on the one hand and least-cost service provision on the other. By doing so, they rely on the legacy of transaction costs economics (see Williamson 2000 for an overview of the field).

Transaction costs economics traditionally addresses questions of make-or-buy in a context of industrial organization. Unit of analysis is the dimension of contracting and the cost-saving possibilities offered by a hierarchical support to otherwise "unassisted" market transactions (Williamson 1985). While this approach has been translated to public choice questions (Williamson 1999), the contribution by Birner and Wittmer is among the first attempts to bring it close to environmental matters. The make-or-buy question originally addressed by Williamson (1985) becomes thereby a question of decentralization and devolution, while the organizational dimension of the management activities at stake is explicitly spelled out with reference to the specificities of environmental matters.

In their proposal, Birner and Wittmer present a particular cost taxonomy against which they assess the comparative efficiency of different management options for protected areas (pure central state management, hybrid state-business management and hybrid state-community co-management). The core of their approach lies in the idea that the elements of such cost taxonomy behave differently for the different governance forms considered. That happens as a function of conceptual dimensions such as "care intensity", "threat to resource" and "measurement costs". Such dimensions have their foundation in Williamson's discriminating alignment hypothesis, distinguishing "asset specificity", "uncertainty" and "frequency" (Williamson 1985). Hagedorn (2008, p. 372) instead suggests "modularity and decomposability of structures" and "functional interdependence of processes" as units of characterization. $\mathrm{He}$ stresses that natural processes require a different treatment than the industrial ones described by Williamson. Entering the debate on the superiority of either approach requires a thorough exploration of the concept of transaction. For the sake of simplicity, we will show that the superiority of the one or the other arrangement emerges from a characterization of the specific task under scrutiny from an organizational point of view.

Transactions are not to be mistaken for transitions, and therefore we are not dealing with the costs of shifting from one governance arrangement to another. Rather we are interested in the day-to-day costs of running a certain governance arrangement. Our interest is based on a simple reasoning: if financial budgets or other types of capacities are limited and constant, increases in the day-to-day costs of running a certain arrangement are bound to decrease its effectiveness. Different governance arrangements imply different organizational setups, whose costs are different on a daily basis. This may affect their effectiveness regardless of any considerations of one-off costs incurred because of the transition. The classification derived by Birner and Wittmer refers to this typology of running costs. They specifically distinguish between production costs and governance costs, the latter encompassing the costs of decision making as well as the costs of implementing a specific policy. In economic jargon, production costs refer to the costs of realizing the core product of a specified activity. Decision-making costs, instead, represent those costs attributed to processes necessary for the core product, e.g. a policy, and its characteristics to be identified against a palette of alternatives. Finally, implementation costs encompass those costs connected with ensuring and enabling the achievement of a certain objective.

Birner and Wittmer (2004) further subdivide both decision-making and implementation costs into direct and failure costs-isolating with the latter the sub-optimality generated by decision-making and implementation failure, respectively. The sum of decision-failure and implementation-failure costs is thereby seen as deviation from a welfare curve (p. 670), i.e., from socially optimal outcomes. We depart from this view as we interpret the emphasis on failure in terms of the high degree of uncertainty surrounding environmental matters. When outcomes are systematically different than expected to a degree where expectations cease to be meaningful, policies are never actually effective because desired outcomes are systematically never achieved. Attention must be paid to those resources a governance arrangement sets aside for dealing with such deviations. If we, however, distinguish risk and uncertainty from ignorance in decision-making (Faber and others 1992), we notice that a decision process can intentionally allocate resources to the first two only. Risk namely corresponds to a set of expected outcomes coupled with probability distributions. Concerning uncertainty, expectations towards alternative outcomes are still there, but probability distributions cease to be meaningful. Ignorance corresponds instead to the absence of expectations towards what may happen next. Whatever loss may emerge from ignorance will do so beyond expectations. The related costs cannot have meaningfully shaped a specific choice, as that choice is bound to be prior to their discovery. Here, we are interested in those costs that affect choices: Ignorance-related failure costs are therefore out of scope.

Furthermore, we consider failure costs merely related to risk and uncertainty as implicit in production and implementation costs. To the extent production and implementation follow from a particular decision-making process, the expectations held will simply translate into specific characteristics of the good produced, of the broader monitoring of it and of the further decision-making expected. This corresponds to projected production, implementation 
and decision-making costs. We have no compelling reason to further tell them apart and remain with a cost taxonomy based on decision-making costs (DM), production costs (P), and implementation costs (I). If we then consider the costs captured by these three categories as a function of the arrangement chosen for a certain task (the production of good $\mathrm{X}$ ) a certain arrangement $\mathrm{A}$ is more cost-effective than an alternative arrangement $B$ if:

$$
\begin{aligned}
& \mathrm{DM}(\mathrm{A} ; \mathrm{X})+\mathrm{P}(\mathrm{A} ; \mathrm{X})+\mathrm{I}(\mathrm{A} ; \mathrm{X})<\mathrm{DM}(\mathrm{B} ; \mathrm{X})+\mathrm{P}(\mathrm{B} ; \mathrm{X}) \\
& \quad+\mathrm{I}(\mathrm{B} ; \mathrm{X}) .
\end{aligned}
$$

At this point, a link must be established with the scale dimension of the arrangement. Birner and Wittmer do so by comparing alternative governance arrangements intrinsically nested at specific levels. Similarly, we refer to the Type I vs. Type II dichotomy. This has implications for the way the scale variable is treated. A purely federalism oriented approach would make it operational as a discrete, or continuous variable ranging between 'national' and 'local'. A multi-level governance perspective as understood here would, instead, rest on a dichotomization between agencies being embedded in pre-existing, multi-tiered, hierarchical politico-administrative structures, or being constituted ad hoc. Cost reasoning would then attach to decision-making, production and implementation costs for the embedded agency being higher or lower than decision-making, production and implementation costs for the ad-hoc alternative.

An example may help clarify this. Assume a hierarchical politico-administrative system encompassing four levels L1, L2, L3 and L4 (from the highest to the lowest). Then assume a certain agency, providing through its operations a good X. In federalism terms, the most basic question would be at what level to nest the agency providing $\mathrm{X}$ (see Benson and Jordan in this issue). This means finding out whether the difference between the benefit of $\mathrm{X}$ provided at level $\mathrm{L}$ and the sum of $\mathrm{DM}(\mathrm{L} ; \mathrm{X}), \mathrm{P}(\mathrm{L} ; \mathrm{X})$ and $\mathrm{I}(\mathrm{L} ; \mathrm{X})$ is biggest for $\mathrm{L}=\mathrm{L} 1, \mathrm{~L} 2$, L3 or L4. Obviously, expressing both the benefit of $\mathrm{X}$ and the costs related to its provision as a function of the level of provision translates into different arrangements foreseeing one central agency providing $\mathrm{X}$ uniformly at L1 as opposed to several low-level agencies providing X locally at $\mathrm{L} 4$, or to intermediate options for $\mathrm{L} 2$ and L3. Differences in the cost functions may then emerge basically in the presence of economies of scale (explained below) and of a degree of spatial variation of preferences across territorial units (Marks and Hooghe 2000). Within such framework, the principle of fiscal equivalence, as laid out above, would take the spatial extent of $\mathrm{X}$ for given and claim that $\mathrm{L}$ will tend towards it.

When contrasting the set-up of Type I and Type II arrangements, the question is a different one: Is $\mathrm{X}$ provided at the lowest cost through an agency embedded in the politico-administrative structures encompassed by the L1to-L4 hierarchy, or should it be provided by an agency outside it? Rationale behind such thought is that the space between L1 and L4 may be conceptualized as a continuum in physical terms, but it is certainly not so in terms of preexisting politico-administrative structures. Here environmental matters make a difference: If the good at stake is not a purely industrial commodity and has, instead, a significant link to ecological dimensions, its territorial extent is likely to fall somewhere in between, say, L2 and L3. The size of a forest, for example, may exceed the size of a jurisdiction at L3 level without necessarily being as big as L2. This would mean that the management of that forest (the good $\mathrm{X}$ ) involves at least two but not all jurisdictions at L3. If that is the case, $\mathrm{L} 2$ is oversized for providing $\mathrm{X}$ : In federalism terms, it would have more contributors than beneficiaries. L3, however, is undersized: Only the L3 jurisdictions covered by the forest (let us first assume uniformly) will be involved matching beneficiaries and contributors. Though the forest is one, thus the two jurisdictions will have to coordinate action. This is costly and may be likely to duplicate efforts. If we then release the uniformity assumption so that only part of the respective two jurisdictions host the forest mentioned above, the coordination efforts will grow as the management of the forest involves a number of L4 jurisdictions crossing an L3 boundary. If we consider that the interconnectedness of ecosystem features makes it likely for the provision of $\mathrm{X}$ to have plural consequences at different scales, we will see that the costs of coordination across jurisdictions necessary for (the benefit of) matching beneficiaries and contributors is likely to become prohibitive. Let us however assume that, within the pre-existing tiers, it is possible to identify a level that strikes the best compromise. Reasons remain for one to wonder whether maybe:

$$
\begin{aligned}
& \mathrm{DM}(\text { “'AdHoc"; } \mathrm{X})+\mathrm{P}(\text { “AdHoc"; } \mathrm{X}) \\
& +\mathrm{I} \text { (“'AdHoc"; } \mathrm{X})<\mathrm{DM} \text { (“"Embedded"; } \mathrm{X}) \\
& +\mathrm{P}(\text { ("Embedded"; } \mathrm{X})+\mathrm{I} \text { ("'Embedded"; } \mathrm{X})
\end{aligned}
$$

where DM("AdHoc";X) expresses the decision-making costs for an agency created ad-hoc for the provision of the good X, while DM("Embedded";X) expresses the decision-making costs for an agency producing the same good $\mathrm{X}$ from within pre-existing hierarchical administrative structures. Similarly for the other cost categories.

The link with Marks and Hooghe's Type I vs. Type II dichotomy is clear. Yet there is more because the characterization behind their dichotomy relies on a second dimension: The single-task vs. multiple-task character of an agency. The link to costs seems straightforward in that a multiple-task agency has opportunities for economies of 
scope that a single-task agency does not have. There is, however, a hidden and counter-intuitive implication: The choice of level has moved away from economies of scale to economies of scope.

Economies of scale are those cost savings that one achieves by spreading fixed costs over a high number of production units. A simplified example could be that the same police department would prove less costly (per intervention) if operating at L3, intervening almost every day, than if operating at L4 and intervening, say, once or twice a month. Economies of scope, instead, refer to the savings obtained by bundling different activities together. It may be, for example, less costly to entrust the aforementioned police department with the additional task of traffic oversight compared to having a dedicated corps for that. Such consideration depends little on how much traffic oversight is needed and more with the two activities (crime-related police operations and traffic oversight) having compatible, or even synergetic characteristics.

The federalism question posed above reflects a trade-off between the spatial variation of preferences and the economies of scale that can be achieved via centralization. In terms of multi-level governance, the trade-off is instead between the costs of an ad-hoc constituted, dedicated special agency and the economies of scope that can be reaped by bundling the same activity within the appropriate tiers of pre-existing bureaucratic structures. This means that when addressing the "embedded" vs. "ad-hoc" question as in (2), the relevant economies of scale as in (1) have been reaped already.

We can now put the above idea in analytical terms: In light of the Type I vs. Type II dichotomy presented by Marks and Hooghe, with an eye on Skelcher's interpretation of special agencies in Type II settings, we can characterize agencies along two dimensions, as shown in Table 1: Agencies being single-purpose vs. multi-purpose entities and agencies nested in pre-existing administrative hierarchies vs. agencies created ad-hoc. Four logical idealtypes emerge; two of them, though, can be dismissed. An ad-hoc, multi-purpose agency is logically inconsistent: Nothing can be "ad-hoc" for a multitude of things (e.g., tasks) at the same time. Instead an embedded, single-purpose agency can be dismissed under the assumption that its embeddedness forces a degree of integration and tasksharing with the rest of the administrative structure, violating the single-purpose character. What remains are the two categories by Marks and Hooghe/Skelcher.

Table 1 Ideal-typical agencies in Marks and Hooghe's characterization

\begin{tabular}{lll}
\hline & Embedded & Ad-Hoc \\
\hline Single purpose agency & - & Type II \\
Multiple purpose agency & Type I & - \\
\hline
\end{tabular}

Having produced a cost taxonomy along Birner and Wittmer (2004) and having characterized Type I and Type II governance arrangements in terms of agency embeddedness and single-purpose vs. multi-purpose connotation, we now have to explore the link between the two to structure expectations towards the superiority of either approach. In order to do that, a characterization of the task at hand is necessary. At this point, matters of space forbid us to proceed fully deductively, providing a catalogue of all operations environmental agencies do and classifying them along a set of dimensions leading to specific cost factors. We therefore have to narrow the focus of the analysis. We will do so by referring to the Venice case focusing only on those specific activities undertaken by the environmental agencies involved.

\section{Fishery Versus Remediation in Venice Lagoon}

Located in north-eastern Italy, Venice Lagoon encompasses several protected areas which survive on a delicate balance between conditions of sedimentation and erosion. Both anthropogenic and natural factors have severely compromised such balance so that the lagoon in its present configuration relies to a large extent on human intervention. The city of Venice, built in the middle of the lagoon, is flood prone. Increasing erosion and rising sea level threaten the survival of the habitats of the lagoon hosts. This translates into the need to constantly intervene in the lagoon's morphology, reshaping its bottom in order to counterbalance erosion, which also preserves Venice from flooding and the habitats from disappearing. Erosion is inevitable to the extent it comes from natural phenomena and/or phenomena that are an exception (e.g. sea level rise). If it is caused by specific human activities instead, the question arises whether their regulation is appropriate.

In the context of this article, two activities are key: On the one hand, the remediation activities dealing with the lagoon's morphology; on the other hand, the commercial clam fisheries. Two goods are most directly at stake: The good "morphological remediation" $(\mathrm{R})$ and the good "clam fishery produce" (F), $\partial \mathrm{R} / \partial \mathrm{F}$ expressing their relationship. The provision of both goods is seen as a function of their regulatory setting. Along with Ostrom (1990), this moves the analysis from matters of operational choice (how much R, F given $\partial \mathrm{R} / \partial \mathrm{F}$ ) to questions of collective choice (how rules on operational choice are decided upon; how $\partial \mathrm{R} / \partial \mathrm{F}$ is thereby accounted for) and constitutional choice (how rules on collective choice are produced). We then express the latter two in scale terms as derived above.

From the 1990s, commercial clam fishing has had a significant socio-economic importance in Venice Lagoon (Granzotto and others 2001, Longo and Rosato 2004). It has, however, detrimental effects on the lagoon morphology 
because of the specific technology used, i.e. motorized trawlers carrying suction-dredging devices. The interventions necessary to restore the morphological damages it causes generate monetary costs estimated at $50 \%$ of the sales revenues (Granzotto and others 2001, p. 51), raising the question about the sector's profitability. That question becomes indeed compelling as soon as reference is made to the scale dimension of the arrangements involved.

The harvesting of the clam resource is subject to a licensing system run by the Province of Venice, which will be referred to as "the Province" from here on. The licensing scheme was introduced to avoid the likely depletion of the resource under open access. The licensing system represents only an intermediate step towards the officially endorsed goal of establishing an aquaculture regime. A system of aquaculture is indeed considered superior in both economic and ecological terms. Instead, the morphological remediation activities are undertaken by a public-private entity encompassing the Venice Water Authority ("Magistrato alle Acque di Venezia") and CVN ("Consorzio Venezia Nuova"), a consortium of middle-sized and large Italian companies operating on coastal and infrastructural engineering projects and realizing similar interventions in the lagoon as a single concessionaire under exclusivity terms. The integrated organizational structure resulting from their combination, from here on referred to as MAV/CVN, is nested at a national level while it operates within the lagoon only. This is exceptional. Within Italy's four-tiered politico-administrative set-up (encompassing national, regional, provincial and communal levels), such matters usually belong to regional administrations. The regions then have the possibility of a downstream delegation towards the provinces as they do, for example, in the case of the fishery regime.

What results from a similar arrangement are the following:

- The Province entitles the fishery sector to a certain level of operation, producing private revenues and employment circumscribed to its territory.

- The sector is simultaneously allowed to produce a certain degree of nuisance through the morphological damages connected with its operations.

- Recovering such damages is not a function of the administration of the Province, but of MAV/CVN, producing costs.

- Being such costs born by MAV/CVN, they are born at national level and not at provincial level.

- This results in a transfer of wealth from national, public pockets to provincial, private ones.

- The present situation is therefore not compatible with the Polluter Pays Principle endorsed by the Water Framework Directive.
The different levels, at which the agencies are nested are at the core of the wealth transfer identified above. In our interpretation, Olson would forecast a rescaling of the agencies involved here to internalize the transfer of wealth unless prohibitively complex: specifically, remediation activities at province level or Fishery Management at national level. The re-scaling did not happen, nor did an environmentally superior technological fix (aquaculture), which is available. Hence, there must be something about this arrangement that explains its persistence. This must be so despite the very same arrangement being officially considered sub-optimal, as implicit in its connotation of transitory phase towards aquaculture.

Explaining the persistence of the current arrangement is certainly a complex endeavor, exceeding the scope of this article. However, there is a scale-related aspect we will concentrate on, which is in line with the theoretical exploration above: The question, namely, whether a rescaling of the agencies involved would solve the problem, or whether it would shift it. Specifically, would a rescaling, aimed at internalizing the abovementioned transfer of wealth, simultaneously lead to costlier agency operations? We believe so. In particular, we argue that, despite the wealth transfer, the specific choice of level for both agencies is likely to produce least-cost arrangements for the tasks the agencies are entrusted with. We will substantiate this argument in the next section.

\section{Agency Design and the Costs of Fishery Management and Morphological Remediation}

The ideal types developed by Marks and Hooghe/Skelcher constitute a good approximation of the arrangements concerning fishery management and morphological remediation in Venice Lagoon. With reference to the multi-purpose vs. single-purpose character of an agency as well as to its position within vs. outside established administrative tiers, we are able to recognize a Type I setting for what concerns fishery management, while remediation resembles a Type II arrangement. Revolving around the operations of the Province's administrative branch, fishery management is firmly embedded in the regular four-tiered, hierarchical administrative structure. Such organization is multi-purpose by nature, dealing with the environment as well as with education, tourism, welfare, cultural promotion and so on. MAV/CVN, instead, was created with one purpose in mind: Remediation of Venice Lagoon. It works beyond existing administrative units and jurisdictional boundaries, focusing on a comparatively narrow and specialized set of tasks. 
What exactly are the tasks entrusted to both agencies and how can we characterize them in relation to decisionmaking, production and implementation costs? The Province is a full-fledged politico-administrative jurisdiction in that it has elected representatives producing regulations and an administrative body executing them. Concerning fishery policy and the licensing system in particular, the local parliament issues regulations specifying quotas, permitted techniques and fishing areas, while the administrative branch has the task of materially issuing the licenses. Monitoring the fishermen's compliance to fishery regulations constitutes a police matter. It is not the responsibility of the Province but of the local territorial subdivision of the Guardia di Finanza, a special police corps relating to the national Ministry of Finance.

In comparison, MAV/CVN, is entrusted with remediation works in the lagoon. Such works encompass medium and large-scale infrastructural projects, which, in the light of the lagoon's unique configuration, require innovation and research as well as a high degree of specialization. Moreover, dealing with flood protection, MAV/CVN is required to act swiftly and effectively for the preservation of assets of national interest and ultimately for the safeguarding of a world heritage. This translates into a continuous process of information gathering concerning the state and the evolution of the lagoon. This is coupled with the development and tailoring of technical solutions for specific problems which subsequently need to be decided upon, put in place and monitored in their realization.

The next step in our analysis consists in linking the above activities to decision-making, production and implementation costs. Considering fishery management, production costs refer to the process of issuing licenses, while decision-making costs are incurred in definition of a fishery policy for the lagoon. Finally, implementation costs are mainly the result of fishery monitoring activities, issuing fines and prosecuting transgressors. On the morphological remediation side, decision-making costs refer to the development and selection of alternative technical solutions mitigating, or adapting to those phenomena causing the disappearing of particular morphological features of the lagoon. Production costs refer to the physical realization of such technical solutions, while implementation costs refer to supervising their realization in compliance to the planning.

Having established a link, however simplistic, between the tasks and the cost taxonomy derived above, the question we intend to address is whether scale-related variations are likely to increase costs. As highlighted above, the scale question is not understood here in terms of the level at which it is best to embed a certain agency. Instead, it is a matter of whether it is best to attribute a certain task to a multipurpose agency embedded in pre-existing, multiple-tiered politico-administrative hierarchies as opposed to constituting ad-hoc single-task, special agencies outside them. This is equal to the question whether a Type I setting would represent a least cost option, or whether a Type II arrangement would do so instead.

Analytically, we can formulate the following hypotheses:

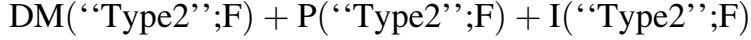

$$
\begin{aligned}
& >\mathrm{DM}(\text { ('Type1" } ; \mathrm{F})+\mathrm{P}(\text { 'Type1' } ; \mathrm{F})+\mathrm{I}(\text { '“Type1" } ; \mathrm{F}) ;
\end{aligned}
$$

while

$$
\begin{aligned}
& \mathrm{DM}(\text { (“Type2' ;R) + P(“'Type2'”;R) + I(“'Type2' ;R) }
\end{aligned}
$$

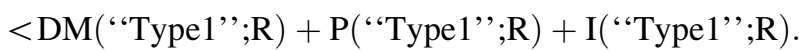

where $\mathrm{F}$ and $\mathrm{R}$ refer to fishery management and to morphological remediation, respectively. For the reader's convenience, we re-labeled Type I and Type II settings using Arabic numerals in the formulas. With an eye on possible incommensurability issues in adding up the different elements above, we restricted our analysis to questions of dominance. Specifically, the condition in (3) is certainly respected if DM("Type2";F) > DM("Type1";F), $\mathrm{P}($ "Type 2 ";F $)>\mathrm{P}($ "Type $1 " ; \mathrm{F})$ and $\mathrm{I}($ "Type $2 " ; \mathrm{F})>$ I("Type $1 " ; F)$ at the same time, regardless of the possibility to conflate them into a single dimension (similarly for (4)). The six, pair-wise comparisons obtained are dealt with singularly in the following. The general terms of the analytical approach used are depicted in Fig. 1: For a general task, sub-activities (intuitively: preference uptake, production, verification etc.) take place that are affected by certain organizational dimensions (coordination across layers, possibilities for economies of scope, spatial variation of relevant preferences, degree of specialization etc.). Such dimensions play out differently according to the type of arrangement chosen, and therefore lead to different costs.

DM(“'Type2'”;F) > DM(“'Type1',;F)

Intuitively, defining clam harvesting areas, quotas and techniques has to be done harmoniously across the lagoon. The territorial extent of the Province matches almost perfectly that of the lagoon. This implies that performing this task through agencies at lower levels such as municipalities, each one covering only a fraction of the lagoon, would require costly coordination efforts. Instead, regulating fisheries at a higher level through a regional agency for fishery management would require it to be able to differentiate between inland fisheries and lagoon fisheries. A similar setup would de facto resemble an agency at provincial level, but would miss out on possibilities to channel the preferences of the lagoon's 
Fig. 1 Agency design and transaction costs

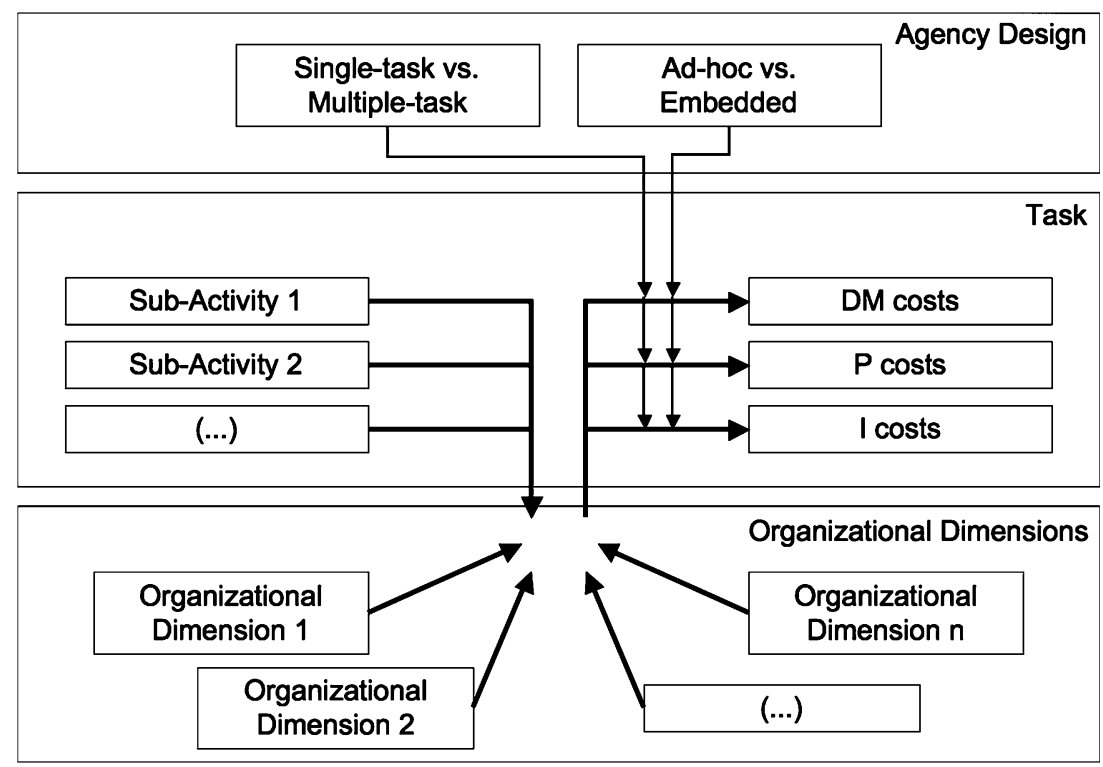

dwellers, implying higher decision-making costs. In this sense, the identity of scale between the Province and Venice Lagoon is a convincing reason to assign lagoon fishery management tasks to the Province.

This shows that DM("Type2";F) is arguably minimal for the Province compared to other levels. We need this to show that a special agency ad-hoc would not be able to perform the same at lower decision-making costs. As above, a similar agency, operating at a provincial level, but detached from the Province would need to set up channels for preference uptake from scratch. This corresponds to higher decision-making costs compared to the Province which has them already in place. Hence, the only way for such costs to be comparatively lower is to allow the agency to operate independently of the constituency's preferences. To the extent the Region, currently delegating to the Province, would still be responsible for fishery management and simply act through a special agency, its decisionmaking costs do not change. These costs are likely to be higher than those of the Province and have to be added to those internal to the ad-hoc agency and to those coming from the mutual coordination. We may thus expect DM("Type2";F) > DM("Type1";F) in the sum.

$\mathrm{P}($ “'Type2'”;F) > P(“'Type1'”F)

Plausibly, production costs are likely to be lower for the Province than for an ad-hoc structure performing the same task. In this, both the multi-purpose and the embedded character of the Province play a role. First, the bureaucratic apparatus of the Province is easily able to reap economies of scope by dealing with a number of different issues. Setting up a bureaucracy from scratch and running the licensing system would arguably be more costly. Furthermore, the embeddedness of the Province may allow it to capitalize on the structures of other tiers above or below at a comparatively lower cost than its adhoc counterpart. Ideally, there may be economies of scope in bundling bureaucratic tasks connected with the licensing system to other activities the Province does in cooperation with e.g. the Municipalities. In comparison, an ad-hoc agency possibly relying on municipal structures to issue the licenses (e.g. giving fishermen the possibility to hand in documents at the closest municipality, rather than at the agency's own facilities) will need to set this up and run it independently. The Province may have a number of similar initiatives, possibly making them less costly on an individual basis. In terms of productions costs, the Province seems superior to a special agency for the task of running the licensing system. We may thus expect $\mathrm{P}$ ("Type2";F) >P("Type1";F).

I('“Type2'”; $)>$ I(“'Type1'”F)

As far as implementation is concerned, monitoring and enforcing the clam fishery regime is a competence of police authorities. Prima facie, there is no reason to assume that the costs of police operations in ensuring compliance to a certain policy depend on the design of the agency that has produced the policy at stake. Specifically, it seems safe to assume that police operations ensure a homogeneous compliance to a number of Type I and Type II arrangements at the same time. Nonetheless, it is worthy to explore a possible feedback mechanism from the decision-making process. If DM ("Type2";F) > DM("Type1";F), a higher number of policy cycles may be necessary for a certain arrangement to be established. In particular, it is plausible that a higher number of adjustments be necessary. If, by chance, noncompliance to the fishery regulations by the fishermen is correlated to the amount of time the arrangement requires 
before it is up and running, we may indeed expect $\mathrm{I}($ "Type 2 ";F) > I( "Type1";F). Most importantly, the possible feedback on decision-making costs suggests that implementation costs may be relevant for a cost-driven agency design choice even if they do not fall directly on the agency itself.

\section{DM(“'Type2”;R) < DM(“'Type1'”; $)$}

As an agency operating outside established politicoadministrative structures, decision-making costs internal to the MAV/CVN can be expected to be comparatively low. As stated above, we expect this to hold true only if the agency is not required to uptake preferences. This raises the question of which preferences enter into how the agency operates. $\mathrm{MAV} / \mathrm{CVN}$ operates within the boundaries of the Province. It deals with safeguarding a site of national interest, so that the relevant set of preferences ideally spans across the whole nation. We are dealing with a multi-tiered decision process involving actors all along the implementation chain from the national to the communal level. Within the regular hierarchical structure, similar processes require a degree of coordination on substantive issues, increasing expenses for staff and organization as well as taking more time. Instead, the preference uptake process pre-ordered to the operations of MAV/CVN represents the shortest decision chain possible by collapsing national, regional and provincial decision-making into two dedicated and slightly differently focused coordination fora: The Safeguard Commission and the Committee for Coordination and Control. The "remaining" decision-making is considered technical in nature and delegated to MAV/CVN. We may thus expect DM(“Type2";R) < DM("Type1";R).

$\mathrm{P}($ “'Type2”, $\mathrm{R})<\mathrm{P}($ “'Type1'”; $)$

MAV/CVN represents a single-purpose agency. Production costs are likely to be high in light of the missing synergies with other tasks. Nonetheless, given the high degree of specialization required, economies of scope seem to be unlikely. The activities performed through MAV/CVN can be reasonably thought of as so different from the administrative business-as-usual that little can be saved by bundling them with other tasks. No savings or synergies can be reaped within a multi-purpose agency as in a Type I setting. A single-purpose special agency as in Type II arrangements seems to be the most cost-effective option. For this typology of activity, one may expect $\mathrm{P}$ (“Type2'”;R) $<\mathrm{P}($ “'Type1"';R).

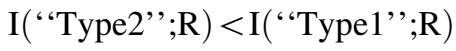

Both the jurisdiction of the Province and the territorial extent of MAV/CVN operations match the ecological boundaries of the lagoon. If remediation was a competence best provided at provincial level, the prima-facie expectation would be that implementation costs are equal for the two arrangements. We know, however, that remediation is a national matter, so that the relevant question is whether a national, multi-purpose agency integrated over four tiers can perform verification activities in a less costly manner than a dedicated one. Intuitively, we would say it can't. The reason for this is the required coordination stretching across three of the four tiers. Certainly, the hypothetical national agency will have ramifications at the Province level that could take on the remediation-related verification activities and report back to the national level. Nonetheless, the remediation activities in Venice Lagoon can be reasonably thought of as sufficiently exceptional and that a similar agency would not be able to bundle the related verification with those it does otherwise. To the extent that agency would need to put dedicated efforts into monitoring the remediation activities, its cost are likely to resemble those of an ad-hoc, Type II special agency. Such costs, however, would be augmented by the additional coordination with the other tiers. In the sum, we can expect I("Type2";R) < I("Type1";R).

The above seems to suggest that both agencies represent least-cost options for the tasks they are set to fulfill. While the choice of a nested, multi-purpose agency seems appropriate cost-wise for the fishery regime, a single-purpose agency with a jurisdiction based on ecological grounds seems best suited for the remediation regime. Although the multi-level governance setting around Venice Lagoon organizes the competent authorities for fisheries and remediation in very different ways, their respective structures seem to provide for least-cost operations. This suggests that (1) The Province may indeed be the least-cost level at which to run the licensing system, which is best run from within the pre-existing politico-administrative structures. It also suggests that (2) Remediation is possibly best dealt with at national level through an ad-hoc agency relying on a coordination forum, at least as far as costs are concerned. Moving away from the present arrangements is likely to inflate costs. The analysis seems to confirm the presumption of efficiency concerning the two distinct arrangements. If this is the case, any attempt at solving the currently problematic relationship between remediation and clam fishery by introducing changes in the Type I/Type II profile of the arrangements at stake will come at a cost: That of having agencies which operate at comparatively higher costs for what concerns decision-making, production and implementation.

\section{Conclusion}

This article has conceptually linked scale issues in environmental matters to the dimension of costs in agency 
design. It has subsequently approached a specific problem affecting the present arrangement in Venice Lagoon. The analysis is led in scale terms, proxied via the Type I vs. Type II dichotomy as proposed by Hooghe and Marks (2003), and suggests that the present arrangement may represent a least-cost option for the tasks considered. We may conclude that scale-related solutions to the problem at hand (the apparent, scale-dependent incompatibility with the Polluter Pays Principle) are likely to undermine the advantage of the present arrangement in terms of least-cost operations for the agencies involved. In this final section, we intend to discuss the robustness of this analysis, the implications of its findings for the problem in Venice, and possible pathways for future research.

Concerning robustness, it is important to keep the exploratory character of the present article in mind. Our analysis suggests that, concerning costs, Type II arrangements may have an edge over their Type I counterparts for certain tasks, while this may not be the case for other tasks. This is intuitive, shifting the question to the conditions under which one type is preferable to the other. Such conditions have been explored by characterizing the tasks at hand in their organizational and fundamentally bureaucratic dimension with an eye both on the agency characterization suggested by Hooghe and Marks (2003) and on the cost taxonomy we derived from Birner and Wittmer (2004). As little or no information is available concerning the administrative side of the Venice context, the two aspects have been linked resting on plausibility reasoning only and thus with an openly speculative approach.

In the absence of data, we have embarked on a thought experiment: The insights produced as a result may now justify efforts in terms of further research and empirical validation. Similar efforts would certainly need to target the actual organizational setup of the two agencies as well as the involved bureaucrats' perceptions concerning the likely dynamics of the cost factors. While the analysis here rests on hypothetical potentials for economies of scope, particular attention shall be given to the actual possibilities for such savings. Only then will it be possible to confirm the pair-wise comparisons at the end of the previous section. If, however, that could be granted, what implications would our findings have for Venice Lagoon as well as for settings presenting the same conditions?

We have found out that the current overall arrangement is likely to ensure least-cost operations in morphological remediation and in fishery management. This is so even in spite of allowing for a transfer of wealth and holding onto it regardless of the availability of a superior alternative. The transfer of wealth is not compatible with the Polluter Pays Principle endorsed by the European Water Framework Directive. Thus, there is a chance that an alternative arrangement becomes mandatory where a sector (and a level) is not able to rely on wealth transfers from another one. Our analysis suggests that if such an alternative is sought after via a rescaling of the present overall arrangements (e.g. remediation led by the Province in a Type I setting; fishery management by MAV/CVN in a Type II arrangement), it will come at higher decisionmaking, production and implementation costs. If that is the case, internalizing the problem through a better "fit" would not solve it but shift it instead. A different interplay between the two agencies must be sought after supporting the idea of a trade-off between fit and interplay as in Moss (2003, 2004).

While this study has demonstrated the value of combining multi-level governance and economic analysis, a number of research questions remain to be explored in more detail. On one hand, there is an obvious research gap with regard to assessing the governance costs of different institutional arrangements beyond the two scenarios analyzed in this article. Such an analysis would, for example, include forms of self-governance, or participatory decision making (also see Newig and Fritsch 2009). On the other hand, further research is needed to explore the mutual relationships of Type I and Type II governance arrangements when they coincide in time and place. In his valuable work, Skelcher (2005) proposed four ideal types of how these two modes of governance could relate to each other (parallel, complementary, incorporated and oppositional). A more thorough theoretical conceptualization as well as empirical analysis is needed.

With reference to the Venice case, further research seems worthwhile concerning the actual coordination mechanisms between the two sectors. As the present study has cautioned against rescaling solutions, the interest goes now to analyzing the problem as a product of the motivation the different decision-makers hold, focusing on how new coordination mechanisms could instead create incentives towards a different overall arrangement without a redesigning of the agencies involved. In particular, we see a promising extension of the present inquiry in testing whether the persistence of the current arrangements can be understood in terms of symbolic policy (Blühdorn 2007). If it were possible to show that the present situation (wealth transfer included) is actually beneficial to the decisionmakers on both the fishery and the remediation side, the national taxpayer would remain alone in experiencing a net loss from the current arrangement. In that case, new interplay mechanisms would need to involve, or at least be transparent towards the national taxpayer in order to make any difference.

Finally, the present article shows a possibility for screening scale-related policy options along with the cost profile of the governance arrangements involved. The relevance of this approach goes beyond the Venice case. 
Applying transaction costs economics to alternative forms of governance, we have been able to test, albeit speculatively, the presumption of efficiency (via least-cost operation) of the present arrangements against their scale dimension. A similar endeavor can be undertaken whenever rescaling seems to constitute a policy option for a certain issue to be addressed. By testing the presumption of efficiency of a given arrangement against scale, it is possible to determine whether the arrangement happens to be in a situation of least-cost service provision, or whether there may be possibilities for additional cost reductions via rescaling. In the first case, one would need to either balance off the benefits of the planned rescaling with the increase in costs it implies, or search for options that do not involve rescaling. In the second case, the direction of the rescaling compared to the cost reductions would determine whether there is a double dividend (cost reductions plus benefits of rescaling), or whether the rescaling would worsen an already suboptimal situation.

Acknowledgments This research was supported financially by the European Union (European Commission, Marie Curie RTN GoverNat, contract No. 0035536, www.governat.eu). Between 2005 and 2007, the first author of this article worked as an assistant for a member of Ufficio di Piano, an expert board advising the Italian Government on the management of Venice Lagoon. The theoretical and conceptual parts were elaborated after 2007 within GoverNat Multi-Level Governance of Natural Resources: Tools and Processes for Water and Biodiversity, a Marie Curie Research Training Network funded by the European Commission under the 6th Framework Program. The authors would like to thank Jouni Paavola, Heidi Wittmer, Felix Rauschmayer, Anna Wesselink and three anonymous reviewers for their valuable comments on earlier drafts of this article.

Open Access This article is distributed under the terms of the Creative Commons Attribution Noncommercial License which permits any noncommercial use, distribution, and reproduction in any medium, provided the original author(s) and source are credited.

\section{References}

Adler JH (2005) Jurisdictional mismatch in environmental federalism. New York University Environmental Law Journal 14:130-178

Birner R, Wittmer H (2004) On the 'efficient boundaries of the state': the contribution of transaction-costs economics to the analysis of decentralisation and devolution in natural resource management. Environment and Planning C: Government and Policy 22: $667-685$

Blühdorn I (2007) Sustaining the unsustainable: symbolic politics and the politics of simulation. Environmental Politics 16:252-278

Faber M, Manstetten R, Proops JLR (1992) Humankind and the environment: an anatomy of surprise and ignorance. Environmental Values 1:217-241
Granzotto A, Franzoi P, Longo A, Pranovi F, Torricelli P (2001) La pesca nella laguna di Venezia: un percorso di sostenibilità nel recupero delle tradizioni. Lo stato dell'arte (Fisheries in Venice lagoon: a sustainability path that values traditions. State of the art). Accessed online September 13, 2008: http://www.feem.it/ NR/rdonlyres/5D1D7BBF-AEA4-4E7F-9A4F-521519E61C45/ 21/rapp0201.pdf

Hagedorn K (2008) Particular requirements of institutional analysis in nature-related sectors. European Review of Agricultural Economics 35:357-384

Hooghe L, Marks G (2003) Unraveling the central state, but how? Types of Multi-Level Governance. American Political Science Review 97:233-243

Jordan A (2001) The European Union: an evolving system of multilevel governance. or government? Policy \& Politics 29:193-208

Longo A, Rosato P (2004) La piccola pesca nella gestione "sostenibile" delle risorse alieutiche della laguna di Venezia: un'analisi basata sulla teoria dei "commons" (Small scale fishery and the "sustainable" fishery management in Venice lagoon: an analysis based on the theory of the "commons"). Accessed online September 13, 2008: http://www.feem.it/NR/rdonlyres/ 89A53B70-51C7-4135-A5D3-D7B9FA86B98/1117/12004.pdf

Marks G, Hooghe L (2000) Optimality and authority. Journal of Common Market Studies 38:795-813

Marks G, Hooghe L (2004) Contrasting visions of multi-level governance. In: Bache I, Flinders M (eds) Multi-level governance. Oxford University Press, Oxford, pp 15-30

Moss T (2003) Solving problems of 'fit' at the expense of problems of 'interplay'? The spatial reorganisation of water management following the EU Water Framework Directive. In: Breit H, Engels A, Moss T, Troja M (eds) How institutions change: perspectives on social learning in global and local environmental contexts. Leske + Budrich, Opladen, pp. 85-121

Moss T (2004) The governance of land use in river basins: prospects for overcoming problems of institutional interplay with the EU Water Framework Directive. Land Use Policy 21:85-94

Newig J, Fritsch O (2009) Environmental governance: participatory, multi-level-and effective?". Environmental Policy and Governance 19:197-214

Olson M (1969) The principle of fiscal equivalence. American Economic Review: Papers and Proceedings 59:479-487

Ostrom E (1990) Governing the commons: the evolution of institutions for collective action. Cambridge University Press, New York

Paavola J, Gouldson A, Kluvánková-Oravská T (2009) Interplay of actors, scales, frameworks and regimes in the governance of biodiversity. Environmental Policy and Governance 19:148-158

Papadopoulos Y (2005) Taking stock of multi-level governance networks. European Political Science 4:316-327

Skelcher C (2005) Jurisdictional integrity, polycentrism, and the design of democratic governance. Governance 18:89-110

Williamson OE (1985) The economic institutions of capitalism: Firms, markets, relational contracting. The Free Press, New York

Williamson OE (1999) Public and private bureaucracies: a transaction cost economics perspective. Journal of Law, Economics and Organization 15:306-341

Williamson OE (2000) The New Institutional Economics: taking stock, looking ahead. Journal of Economic Literature 38:595-613

Young O (2002) The institutional dimensions of environmental change: fit, interplay and scale. MIT Press, Cambridge 